\title{
A Study of Optimum Timing of Laparoscopic Cholecystectomy in Patients Presenting with Acute Cholecystitis
}

\author{
Hiren P. Vaidya' ${ }^{1}$, Abhishek M. Shah.2, Aditya H. Vaidya ${ }^{3}$, Hemali M. Shah ${ }^{4}$ \\ 1Department of General Surgery, Surat Municipal Institute of Medical Education and Research, Surat, Gujarat, India. \\ ${ }^{2}$ Department of General Surgery, Surat Municipal Institute of Medical Education and Research, Surat, Gujarat, India. \\ ${ }^{3} \mathrm{KEM}$ Hospital and Seth Gordhandas Sunderdas Medical College, Mumbai, Maharashtra, India. ${ }^{4}$ Department of \\ Statistics, Gujarat Commerce College and Research, Surat, Gujarat, India.
}

\section{ABSTRACT}

\section{BACKGROUND}

Laparoscopic cholecystectomy is difficult in acute cholecystitis because the gall bladder is usually thick walled and tensely distended. If the inflammation of the gall bladder extends to the porta hepatis the dissection becomes difficult. The normally thin minimally adherent tissue that invest the cystic duct and artery is markedly thickened and oedematous and may not readily separate from these structures with the usual blunt dissection technique. The duct wall also may be oedematous, thus making its external diameter similar to gall bladder neck and common bile duct. Moreover, operative difficulty substantially increases with time. It is believed that laparoscopic cholecystectomy in acute cholecystitis is having more operative time, more conversion rate and more chance of injury.

\section{METHODS}

We did an observational study to determine the safety, benefits and drawbacks of laparoscopic cholecystectomy within 72 hours of symptoms (and beyond that).

\section{RESULTS}

Total 325 patients underwent laparoscopic cholecystectomy in acute cholecystitis. Among them 110 patients were operated within 72 hours of appearance of symptoms while 215 patients were operated upon after 72 hours of appearance of symptoms. The mean duration of surgery was significantly $(p<0.001)$ less in early surgery group. There was no conversion. There was no serious intra operative complication (injury) in early group. There was no statistically significant post-operative complication in either group. Post-operative stay was significantly less $(p<0.004)$ in early laparoscopic cholecystectomy group. Period of return to work was also significantly less $(\mathrm{p}<0.001)$ in early group.

\section{CONCLUSIONS}

Early (within 72 hours of appearance of symptoms) laparoscopic cholecystectomy can be safely advocated in patients of acute cholecystitis. It does not result in increased conversion rate or increased intra operative complication. Moreover it offers benefits shorter post-operative hospital stay and early return to work than laparoscopic cholecystectomy after 72 hours of appearance of symptoms.

\section{KEY WORDS}

Cholecystectomy, Laparoscopic, Cholecystitis, Acute

\author{
Corresponding Author: \\ Abhishek M. Shah., \\ F 602, Pragati Nagar, \\ Lake View Garden Lane, \\ Piplod, Surat-395007, \\ Gujarat, India. \\ E-mail: abbishek.1988@gmail.com
}

DOI: $10.14260 / \mathrm{jemds} / 2019 / 869$

Financial or Other Competing Interests: None.

How to Cite This Article:

Vaidya HP, Shah AM, Vaidya AH, et al. A study of optimum timing of laparoscopic cholecystectomy in patients presenting with acute cholecystitis. J. Evolution Med. Dent. Sci. 2019;8(52):4016-4019, DOI: 10.14260/jemds/2019/869

Submission 21-08-2019,

Peer Review 12-11-2019,

Acceptance 18-11-2019,

Published 30-12-2019. 


\section{BACKGROUND}

The advent of laparoscopic cholecystectomy has been a significant milestone not only in the treatment of gallstone disease, but also in the evolution of surgical treatment by minimal access. Anecdotal reports of laparoscopic procedure related death and bile duct related injury necessitate viewing laparoscopic cholecystectomy with cautious enthusiasm.(1) With growing experience overcoming the learning curve, selection criteria for this surgery has become more liberal. Most of previous contraindications such as morbid obesity, previous upper abdominal surgery and acute cholecystitis are no longer absolute contraindications. Studies involving open cholecystectomy have suggested that performing surgery within the first 3 days of onset of symptoms reduced the length of hospital stay and recovery time without increasing complications.(2) The appropriate timing for cholecystectomy in the treatment of acute cholecystitis still remains controversial. Reports suggested that early laparoscopic surgery for acute cholecystitis was associated with increased complication rates, prolonged operation times and increased conversion rates.(3) As a consequence, initial conservative management with subsequent elective laparoscopic cholecystectomy became the accepted practice.(4) Delayed cholecystectomy potentially increases the chances of further gallstone related complications and thus farther hospital admission.(5)

How early cholecystectomy is 'early' is not clear in the literature, as this parameter has not been effectively tested in controlled randomized trials. Optimal timing of laparoscopic cholecystectomy for acute cholecystitis still remains under debate.(6) The aim of this study is to evaluate the results of laparoscopic cholecystectomy for acute cholecystitis when laparoscopy is carried out early (within 72 hours from the onset of the symptoms) and late (after 72 hours from the onset of the symptoms). The objective of this study is to determine optimal timing of surgery with regard to patient safety in cases of acute cholecystitis.

The degree of operative difficulty increases substantially over time in acute cholecystitis and surgeons have typically used 72 hours as an arbitrary cut off in degree of difficulty of dissection. Generally, in the first 48 to 72 hours of symptoms the tissue planes are oedematous, but structures are identifiable, and the tissue planes separate without much difficulty. After 72 hours, the tissues become more friable and separate less well, the important structures are less likely to be seen well and there is often more obscure bleeding. For these reasons it is important to consider operating early in acute cholecystitis. Often patients present late after many days of symptoms or the gallbladder appears extremely oedematous and thick walled on ultrasound. Generally, all of these patients should be considered for laparoscopic cholecystectomy unless they are extremely ill or significant comorbidities exist. If the patient goes to the operating room, an attempt at exposure of the Calot's triangle and a trial dissection should be undertaken. If it is determined that safe laparoscopic cholecystectomy cannot be performed, two potential options exist: 1 . Conversion to open surgery or 2 . Cholecystostomy tube placement. An open operation might not offer much additional benefit to a very experienced laparoscopic surgeon and many recently trained surgeons today do not have a great deal of experience performing open cholecystectomy, so that conversion may not be that beneficial to the surgeon or the patient.

\section{METHODS}

The study was conducted at department of surgery, SMIMER hospital from September 2013 to December 2015 on patients presented and hospitalised with acute cholecystitis, of all age groups and gender. Thus, patients taken under this study are based on consecutive sampling and purposive sampling (With purpose of patients having acute cholecystitis). Diagnosis of acute cholecystitis was established on following parameters: 1) clinical presentation which included; a) pain in abdomen. b) Tenderness in right hypochondrium. c) Contraction of the abdominal wall in right upper quadrant. d) With or without fever.e) With or without nausea and vomiting. 2) Contributory laboratory findings. 3) Abdominal ultrasonographic confirmation of the diagnosis by presence of gallstones, gallbladder wall oedema, pericholecystic fluid collection. 4) Intra-operative findings 5) histopathologic examination. All cases undergone laparoscopic cholecystectomy, were studied under two categories: Group A: laparoscopic cholecystectomy performed within 72 hours of onset of symptoms of acute cholecystitis. Group B: laparoscopic cholecystectomy performed after 72 hours of onset of symptoms of acute cholecystitis. The following parameters were analysed: 1) demographic information, laboratory tests and ultrasonographic features. 2) Duration of surgery. 3) Duration of postoperative hospital stay. 4) Incidence of major biliary injury and injury to other organs. 5) Conversion of laparoscopic surgery to open surgery.

Laparoscopic cholecystectomy was performed using standard technique under general anaesthesia. It is an observational study with consecutive and purposive sampling. All patients registered from September 2013 to December 2015 who were hospitalised with acute cholecystitis, of all age groups and gender are considered as sample of study. So, the sample size is 325 patients. Amongst them 110 patients were operated within 72 hours of diagnosis and 215 patients were operated after 72 hours of diagnosis. So, study is based on two non-randomized groups. (Group A: 110 patients, group B: 215 patients).

\section{Statistical Analysis}

Descriptive and Inferential statistics have been carried out in the study. Using descriptive statistics, results on quantitative data are presented in mean $(+/-)$ standard deviation and results on qualitative data are presented in percentage (\%). Using inferential Statistics, significance is assessed at 95\% level of significance. Student $\mathrm{t}$ test (two tailed, independent) has been used to find the significance of study parameters on continuous scale between two groups on metric parameters. Chi-square test, Fisher exact test and Yate's correction has been used to find the significance of study parameters on categorical scale between two groups. Data analysis is done using open EPI software. Microsoft Word and Microsoft Excel used to generate graphs, tables etc. 


\section{RESULTS}

$33.84 \%$ patients were operated upon within 72 hours of onset of symptoms and included in group A. $66.16 \%$ patients were operated upon after 72 hours of onset of symptoms and included in group B. Mean age (Mean \pm SD) for group A is $37.94 \pm 12.82$ years and for group $B$ it is $40.13 \pm 13.92$ years. Group A included $18.19 \%$ males and $81.81 \%$ females; Group B included $24.65 \%$ males and $75.35 \%$ females. Most common presenting complaint was pain in abdomen which was seen in all patients. $46.36 \%$ of patients in group A and $43.25 \%$ of patients in group B were febrile at the time of presentation. One third of the patients $(35.6 \%)$ presented within 24 hours of onset of complaints. Eleven percent of patients were found to have raised temperature $\left(>100^{\circ} \mathrm{F}\right)$. Only $2.5 \%$ of patients had pulse rate more than 100 per minute. All patients presented with tenderness in right hypochondrium. Guarding was present in $71.81 \%$ of group A and $78.60 \%$ of patients of group B. Lump was palpable in $12.30 \%$ cases $(13.63 \%$ in group A and $11.62 \%$ in group B).

Total WBC count between $11000-15000 / \mathrm{cmm}$ was noted in $45.45 \%$ of patients in group A and $55.34 \%$ of patients in group B. Total 18 (5.54\%) patients had serum bilirubin levels more than $2 \mathrm{mg} / \mathrm{dl}(2.73 \%$ patients in group A and $6.98 \%$ in group B). Serum AST, serum ALT and serum ALP levels were found to be elevated only in $13.3 \%, 17.5 \%$ and $11.4 \%$ patients respectively (In $11.82 \%, 16.37 \%$ and $8.19 \%$ patients respectively in group $A$, while in $13.96 \%, 18.14 \%$ and $13.03 \%$ respectively in group B). Majority of patients (72\%) had multiple gallbladder calculi $71.81 \%$ in group A and $72.09 \%$ in group B) while pericholecystic fluid was present in $1.5 \%$ of cases ( $0.9 \%$ in group A and $1.86 \%$ in group B). Wall thickening was present in $72 \%$ of patients $(58.18 \%$ in group $A$ and $79.06 \%$ in group B). Common bile duct was normal in $98.5 \%$ of patients $(99.09 \%$ in group A and $98.14 \%$ in group B).

\begin{tabular}{|c|c|c|c|c|c|}
\hline & 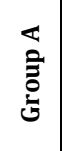 & 象 & & 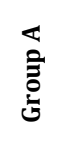 & 气̊ \\
\hline $\mathrm{N}$ & 110 & 215 & WBC (11000-15000/cmm) (in \%) & 45.45 & 55.34 \\
\hline Percentage & 34.92 & 68.25 & Serum bilirubinlevels ( $>2 \mathrm{mg} / \mathrm{dl}$ ) (in \%) & 2.73 & 6.98 \\
\hline Mean & 37.94 & 40.13 & SerumAST (in \%) & 11.82 & 13.96 \\
\hline S.D. & 12.82 & 13.92 & Serum ALT (in \%) & 16.37 & 18.14 \\
\hline Male (\%) & 18.19 & 24.65 & SerumALP (in \%) & 8.19 & 13.03 \\
\hline Female(\%) & 81.81 & 75.35 & Multiple gallbladder calculi (in \%) & 71.81 & 72.09 \\
\hline $\begin{array}{l}\text { Febrile at the time } \\
\text { of presentation (\%) }\end{array}$ & 46.36 & 43.25 & Presence of pericholecystic fluid (in \%) & 0.9 & 1.86 \\
\hline Guarding (\%) & 71.81 & 78.6 & Wall thickening (in \%) & 58.18 & 79.06 \\
\hline Lump & 13.63 & 11.62 & Normal Common bile duct (in \%) & 99.09 & 98.14 \\
\hline $\begin{array}{c}\text { Mean Duration of } \\
\text { Surgery }\end{array}$ & 75.55 & 94.16 & $\begin{array}{l}\text { Standard Deviation of Duration of } \\
\text { Surgery }\end{array}$ & 10.47 & 13.47 \\
\hline \multicolumn{6}{|c|}{ Table 1. Descriptive Analysis (Pre Operation) } \\
\hline
\end{tabular}

\begin{tabular}{|c|c|c|c|c|c|c|}
\hline & N & Mean & S.D. & t-test & p-Value & Conclusion \\
\hline Group A & 110 & 75.55 & 10.47 & - & & $\begin{array}{c}\text { Mean duration of surgery of } \\
\text { group A is significantly } \\
\text { less than group B. }\end{array}$ \\
\cline { 1 - 4 } Group B & 215 & 94.16 & 13.47 & 12.281 & 0.000 & $\begin{array}{c}\text { Table 2. Comparison of Mean Duration of Surgery Using } \\
\text { Independent t Test }\end{array}$ \\
\hline \multicolumn{7}{|c|}{}
\end{tabular}

No patient in group A needed to be converted from laparoscopic to open procedure. In group B, laparoscopic surgery had to be converted in open surgery in 3 patients, due to intra-operative bleeding in 1 patient, due to difficult anatomy in 1 patient and due to adhesions in 1 patient. Duration of surgery was $75.55+/-10.87$ minutes in group A, while it was $94.16+/-13.87$ minutes in group B. The $P$ value is less than 0.001 . It shows that mean duration of surgery in patients operated under group A was significantly less than those operated under group B.

Most patients $(95.38 \%)$ had oedematous gallbladder (96.36\% in group A and 95.38\% in group B). Adhesions were present in $90.70 \%$ cases $190 \%$ in group A and $90.47 \%$ in group B) while cystic duct was normal in $96.92 \%$ cases $(98.19 \%$ in group A and $96.28 \%$ in group B). Intraoperative bleeding was noted in $1.81 \%$ of cases in group A and $7.44 \%$ of cases in group B. Gallbladder perforation was noted in $1.81 \%$ patients in group A and $7.44 \%$ patients in group B. Gallbladder aspiration was done in 2 cases. Bile duct injury occurred in 2 cases of group B. Stone spillage occurred in $0.9 \%$ of cases in group A and $4.18 \%$ of cases in group B.

\begin{tabular}{|c|c|c|c|c|c|c|c|}
\hline & Group A & \multicolumn{2}{|c|}{ Group B } & p & $\begin{array}{c}\text { Total } \\
\text { Patients }\end{array}$ & $\begin{array}{c}\% \text { of } \\
\text { Total }\end{array}$ \\
\hline & No. & $\mathbf{\%}$ & No. & $\mathbf{\%}$ & & & \\
\hline Bile Leak - Yes & - & - & 1 & 00.46 & 1 & 1 & 00.40 \\
\hline Bile Leak- No & 110 & 100 & 214 & 99.54 & & 324 & 99.60 \\
\hline Icterus - Yes & - & - & 3 & 01.39 & 0.5763 & 3 & 00.92 \\
\hline Icterus - No & 110 & 100 & 212 & 98.61 & & 322 & 90.08 \\
\hline Uncontrolled BP & - & - & 3 & 01.39 & 0.5763 & 3 & 00.92 \\
\hline Uncontrolled Sugar & 1 & 0.90 & 4 & 01.86 & 0.8547 & 5 & 01.53 \\
\hline Wound infection & 1 & 0.90 & 9 & 4.18 & 0.2011 & 10 & 03.08 \\
\hline \multicolumn{8}{|c|}{ Table 3. Post-Operative Complications } \\
\hline
\end{tabular}

\begin{tabular}{|c|c|c|c|c|c|c|}
\hline & $\mathbf{N}$ & Mean & S.D. & t-test & $\mathbf{p}$ & Conclusion \\
\hline Group A & 110 & 4.46 & 3.73 & \multirow{2}{*}{2.884} & \multirow{2}{*}{0.004} & \multirow{2}{*}{$\begin{array}{c}\text { Mean duration of } \\
\text { postoperative stay of group A } \\
\text { is significantly less than } \\
\text { group B. }\end{array}$} \\
\hline Group B & 215 & 5.92 & 5.26 & & & \\
\hline
\end{tabular}

Bile leak found postoperatively in one patient of group B. Icterus observed in 3 cases of group B. Surgical site infection occurred in $0.9 \%$ cases in group A and $3.08 \%$ of group B cases. $P$ value is $>0.05$ for all parameters including bile leak, icterus, uncontrolled blood pressure, uncontrolled blood sugar and wound infection. It means there is no statistically significant difference in occurrence of postoperative complications between group A and group B.

Most of the patients (50.15\%) were discharged within 3 days after surgery (60\% in group A and $45.16 \%$ in group B) while $24.92 \%$ patients were discharged between 4 to 7 days after surgery. $55.15 \%$ of patients $(60 \%$ from group A and $45.16 \%$ from group B) were discharged within 3 days of surgery. $20.9 \%$ of patients from group A and $26.97 \%$ of patients from group B (Total $24.92 \%$ ) were discharged within 4-7 days. $19.08 \%$ (17.27\% from group A and 20\% from group B) of patients were discharged in second week. Total of 19 (5.85\%) patients (2 in group A and 17 in group B) were discharged after 2 weeks. Three of them had uncontrolled hypertension, four had uncontrolled sugar and nine of them had surgical site infection. Mean post-operative stay is $4.46+/$ 3.73 days in group A and $5.92+/-5.26$ days in group B. The $P$ value is $p<0.004$. It shows that mean duration of postoperative stay in group A was significantly less than that in group B. Return to work was calculated from the day of surgery.

$97.27 \%$ of patients in group A while $69.76 \%$ of patients in group B returned to work in first week of surgery. Of remaining patients of group B, $25.58 \%$ returned to work in second week and $4.64 \%$ in third week of surgery. $P$ value is 
$\mathrm{p}<0.001$. It shows that period for return to work is significantly less for patients in group A than for those in group B. About two third of the patients, 217 patients $(66.80 \%)$ were found to have acute on chronic cholecystitis on histopathology report (91.81\% in group A and $53.95 \%$ in group B).

\section{DISCUSSION}

Several authors have reported performing laparoscopic cholecystectomy in the face of acute inflammation with success but with a higher conversion rate than for elective laparoscopic cholecystectomy. $(7,8,9,10)$ Lo et al in their prospective study reported that despite longer operative times and postoperative stays for early laparoscopic cholecystectomy (treatment within 5 days) versus delayed laparoscopic cholecystectomy (initial conservative treatment followed by laparoscopic cholecystectomy 3 to 4 months later), the advantage of early laparoscopic cholecystectomy was the reduction in the total hospital stay, from 15 to 7 days.(11) Another prospective study of 105 patients randomized to early laparoscopic cholecystectomy (within 24 hours of diagnosis of acute cholecystitis) versus delayed laparoscopic cholecystectomy (6 to 8 weeks later), reported no significant difference in conversion rate (Early $21 \%$ vs. delayed $24 \%$ ), postoperative analgesic requirement or number of postoperative complications. The early group did have a longer operative time (123 $\mathrm{min}$ vs $107 \mathrm{~min}, \mathrm{p}=0.04$ ); but total hospitalization was shorter ( 8 days $\mathrm{v} / \mathrm{s} 12$ days; $\mathrm{p}=$ 0.001).(12)

Rattner et al attempted laparoscopic cholecystectomy for acute cholecystitis and examined factors that were predictive of a successful procedure.(13) Seven of the 20 patients $(35 \%)$ required conversion to open cholecystectomy. The interval from admission to cholecystectomy in the successful cases was 0.6 days versus 5 days in the cases requiring conversion to open cholecystectomy. Chahin et al examined the relationship between the success rates for laparoscopic surgery and the time from onset of acute cholecystitis symptoms to surgery. The success rate has dropped significantly after the first 4 days.(14) These results have been confirmed in more recent studies. In the study by Shamim disturbed anatomy at Calot's triangle accounted for more than one half of conversions (54.32\%); The reasons of obscured anatomy were acute inflammation (52.27\%), chronic cholecystitis (36.36\%) and aberrant anatomy (11.36\%).(10) In 6.17\% patients, dense adhesions were found between gallbladder and bowel. (3 with the stomach and 2 with the transverse colon). They were difficult to separate laparoscopically, so conversion to open surgery was made. With increasing laparoscopic experience, an inverse trend in conversion rates is seen.

\section{CONCLUSIONS}

Cholecystectomy for acute cholecystitis can be safely advocated in patients presenting within 72 hours of onset symptoms. This does not result in increased major complication rates and conversion rates. Early laparoscopic cholecystectomy is not associated with more conversion to open procedures. Decreased conversion rates result in shorter post-operative hospital stay. Early cholecystectomy is beneficial as patients tend to return to work earlier.

\section{REFERENCES}

[1] Thistle JL, May GR, Bender CE, et al. Dissolution of cholesterol gall bladder stones by methyl tert ether administered by percutaneous transhepatic catheter. N Engl J Med 1989;320(10):633-9.

[2] Lee AY, Carter JJ, Hochberg MS. The timing of surgery for cholecystitis: a review of 202 consecutive patients at a large municipal hospital. Am J Surg 2008;195(4):467-70.

[3] Kum CK, Goh PM, Isaac JR, et al. Laparoscopic cholecystectomy for acute cholecystitis. Br J Surg 1994;81(11):1651-4.

[4] Cuschieri A. Approach to the treatment of acute cholecystitis: open surgical, laparoscopic or endoscopic? Endoscopy 1993;25(6):397-8.

[5] Wilson P, Leese T, Morgan WP, et al. Elective laparoscopic cholecystectomy for "all-comers". Lancet 1991;338(8770):795-7.

[6] Navez B, Mutter D, Russier Y, et al. Safety of laparoscopic approach for acute cholecystitis: retrospective study of 609 cases. World J Surg 2001;25(10):1352-6.

[7] Reddick EJ, Olsen DO, Daniel JF. Laparoscopic laser cholecystectomy. Laser Med Surg Adv 1989;7:38-40.

[8] Unger SW, Edelman DS, Scott JS, et al. Laparoscopic treatment of acute cholecystitis. Surg Laparosc Endo 1991;1(1):14-6.

[9] Ibrahim S, Hean TK, Ho LS, et al. Risk factors for conversion to open surgery in patients undergoing laparoscopic cholecystectomy. World J Sure 2006;30(9):1698-704.

[10] Shamim M, Memon AS, Bhutto AA, et al. Reasons of conversion of laparoscopic to open cholecystectomy in a tertiary care institution. J Pak Med Assoc 2009;59(7):45660.

[11] Lo CM, Liu CL, Fan ST, et al. Prospective randomised study of early versus delayed laparoscopic cholecystectomy for acute cholecystitis. Ann Surg 1998;227(4):461-7.

[12] Bailey RW, Flowers JL. Complication of laproscopic surgery. St. Louise: Quality Medical Publishing 1995: p. 416.

[13] Rattner D, Ferguson C, Warshaw AL. Factors associated with successful laparoscopic cholecystectomy for acute cholecystitis. Ann Surg 1993;217(3):233-6.

[14] Chahin F, Elias N, Paramesh A, et al. The efficacy of laparoscopy in acute cholecystitis. Journal of the Society of Laparoendoscopic Surgeons 1999;3(2):121-5. 